\title{
Culture and COVID-19
}

\section{Observations From an Italian American Nurse}

\author{
Victoria Daughen, BSN, RN
}

Holist Nurs Pract 2020;34(4):196-198

"Something's wrong in your head," said the Italian doctor, tapping his skull before exiting the room. Shortly after, I entered to see my classmate, the patient, in hysterics.

Upon obtaining my nursing license, I took a gap year. Most of my time was spent enrolled at an international university in Italy, where I studied as part of a language immersion program. I was generally the only American in my core classes. My classmates and friends were from Somalia, Peru, Syria, Azerbaijan, China, Uzbekistan, Russia, Iran, Colombia, Germany, Armenia, Japan, France, Australia, and Switzerland, among others. We were frequently partnered with those who did not share a native language, making it necessary to speak only Italian. Naturally, there were also Italians at the university, studying other subjects.

The classmate whom I visited in the hospital was from Algeria. No interpreters were offered at the Italian hospital. Fortunately, we had 2 Egyptian classmates who assisted when our peer was too ill to speak anything but his native Arabic. I still felt as though we were treading in dangerous waters: when I attempted to explain the word for "seizures" in Italian to my Egyptian classmate, he didn't understand what I meant. We resorted to an online translation program to show the word in Arabic, and he stated he understood. However, as I can't read Arabic, I had no way of verifying the accuracy.

\footnotetext{
Author Affiliation: College of Nursing and Health Professions, Drexel University, Philadelphia, Pennsylvania.
}

The author has disclosed that she has no significant relationships with, or financial interest in, any commercial companies pertaining to this article.

Correspondence: Victoria Daughen, BSN, RN, College of Nursing and Health Professions, Drexel University, 1601 Cherry St, 6th Floor, Room 620, Philadelphia, PA 19102 (victoriadaughen26@gmail.com).

DOI: 10.1097/HNP.0000000000000395
We conversed among each other in Italian, and my role became attempting to understand the foreign health care system. Besides no interpreters, this facility did not provide hospital gowns and potable water outside that of the bathroom sink, nor many other amenities that would be considered standard at an American hospital. The staff did not know that I was an infermiera (nurse), but I doubted it would have mattered. At the end of the day, to the hospital staff, we were stranieri (foreigners).

"Something's wrong in your head," said the Italian doctor to the patient, tapping his skull before exiting the room. The patient's father had died of cancer that had metastasized to his brain. Thankfully, that was not our classmate's diagnosis, but that was all he gathered from this limited explanation. "What's wrong? What has happened?" I said, entering a scene of total distress. While I would have objurgated any American doctor for that kind of performance, many Italians and my other international colleagues would find elements of American health care frankly inconceivable. For example, my Italian health insurance cost about $€ 70$ (around \$75) for 6 months of coverage. Our costs are perceived as astronomical, bordering on inhumane, in the eyes of many foreigners.

My intention is not to present my opinions on the various international infrastructures of health care systems and the behavior of their health professionals: it is instead to highlight the importance of cultural perceptions in times of crisis. Upon discharge (which preceded my classmate having any clue of his diagnosis - he found out when I read him his discharge papers, at home), my classmate was overcome with gratitude toward the Italian health care system. He raved it was the best he had ever encountered, far exceeding his experiences in Algeria. Everything is relative! 
If he ever traveled to the United States, he would have been unaware that it was entirely appropriate to request water, much less ginger ale and orange juice, toothbrushes, and patient gowns, to which Americans are so accustomed. He wouldn't have known it was ok to expect staff to tell you about your diagnosis. Things that we as American nurses view as standard or as a normal expectation may be the furthest thing from normal in another country.

Ephemeral acts may lead to eternal thanks. Taking the extra second to explain a concept (one that even may appear basic at first glance) may make a world of difference. Besides acknowledging a diversified knowledge base, it is equally important to recognize a difference in perceptions.

As a nurse returning to the United States, this extended to having compassion for those with apprehension toward our health care system. Perhaps, cultural sensitivity during a pandemic doesn't sound like an accolade-winning idea. It might not seem like life and death, but it very well may be. What are you, the nurse, going to do when someone elects to surrender his or her life over ethical or cultural convictions?

In nursing school, when I worked as a technician in an emergency department, I was frequently called to do electrocardiograms (EKGs) on female Muslims. Once I studied with Iranian women, having come to Italy fresh from Sharia Law, I understood more of the concept and choices, regarding the hijab. Would a woman, potentially having a heart attack, request to delay an EKG if an all-male staff would see her unveiled?

When I filled a temporary nurse research post during part of my gap year in the United States, it was necessary to consider the mind-sets stemming from a conservative sect of Judaism. These prohibited touch between the sexes. What happened when a patient's gender differed from that of our all-female team? Ultimately, it was possible to strike a balance between religious values and medical necessity. Perhaps, neither of these scenarios are anything particularly new. The needs of an individual patient are discussed everywhere from nursing school to floor meetings, with dietary adjustments and interpreters called for both diverse and idiosyncratic needs. How is this relevant on a mass scale? What does this have to do with a global pandemic?

Contagion derives from contact, which derives from culture. How would an initial request of "social distancing" impact a country where kisses on the cheek are the expected greeting? In a culture where grandparents are revered, would it be unthinkable to avoid the "nonni" (grandparents) for an extended period, particularly when the elderly make up so much of the Italian population? Meanwhile in the United States, we sensationalize boundless freedom over rigid obedience. Some countries may view college students partying on beaches in a time of crisis as shamefully abhorrent, a dishonor worthy of keeping quiet. Here their arguments for their right to celebrate, to exercise their choice, were nationally televised.

Even within the United States, we often accompany our nationality with our ethnicity ("I'm Irish American." "My family is Chinese American."), a peculiarity that other countries may find confusing if their ethnicity and nationality are one in the same. As diverse as our identifications may be, this extends to our recognition of family (which Italian American families, such as my own, claim is "everything"). These cultural values or lifestyle expectations again are relevant, this time regarding hospital visitation policies among ever-changing pandemic protocols.

Restrictions have been enacted during the pandemic. For example, in a pediatric setting, visitation may be limited to 2 parents or legal guardians. Communities with various social complications, such as a high level of incarceration, could draw other family members (such as grandparents or older siblings) into assuming a parental role. During any other time, this individual may have been the support person for a sick child. However, pandemic-produced policies now changed everything as legalities that supported nuclear-or neatly court-provided-structures became the overarching rule.

This could be repetitious in any type of department, at least in one permitting visitors at all. Consider a maternity unit as another hypothetical example. How would new standards impact the single woman who otherwise would have brought her elderly mother? If a surrogate mother is delivering, would a choice have to be made as to which parent could attend? I'm not implying there's an overarching correct answer to cover each quandary. All I hope to emphasize is that the complications of a pandemic are intricately tied to lifestyle, which, paradoxically enough, correlates with our responses to death.

I am neither a hospice nor a critical care nurse, roles in which mortality becomes particularly relevant in the current climate. I won't reiterate basic responses to grief or standard therapeutic communication. 
However, I will highlight certain culturally sensitive elements.

Families may want to be around those who more acutely understand their values. This emphasizes the importance of having a diverse staff. More patients and families may feel as though there is someone who can serve as an advocate to explain the needs of various customs (this does not promote making individual staff assignments based on familiarity; it encourages a unit where a multitude of people are represented). Typically, we rely upon our medical interpreters as excellent linguistic and cultural mediators; now scenarios with a previous "in-person support" expectation may be more difficult during these times centered around stay-at-home efforts.

Regardless of belief, a few things remain universal as we face a trying time in history. We have the freedom from prediction. We can still believe in bliss while recognizing a tragedy. Truthfully, we do not know how events may have unfolded if something was done differently. We are not responsible for surmising a future if something had progressed otherwise, because even that scenario could have been influenced by something unexpected. Hypothetical outcomes do not exist, reality does. We are not obligated to rationalize.

In addition, acknowledging a loss does not exclude a belief in future paradise. It is not wrong to grieve while bearing beliefs regarding afterlife, or of future hope. Our memory can be perceived as bearing a burden or holding a treasure.

From this pandemic, this world-altering experience, we have 3 choices. This is how we handle our perspective, our experience, our hurt, our inspiration, or whatever it is you take from this:

1. Release it. Will you long for what has been surrendered or look forward to a future unburdened?

2. Bury it. Will you tire yourself planting, or are you making a place for something to blossom?

3. Carry it. Is it a weight downward or a force onward?

Your authority is in the choices you have, your greatness is in the decisions you make.
During the COVID-19 epidemic, this applies to not only our nurses but also our administrators and regulatory bodies, extending on a larger scale beyond even our hospitals. Some employees are nudged to donate sick time to their colleagues, while staff and community members are encouraged to donate PPE (personal protection equipment). Do we recognize siblings, or do we recognize parents, as being responsible for care?

I understand it is chaotic for regulatory bodies, so we must be understanding of an inability to provide clear directions. Where were these institutions when it was chaotic for nurses with obscene patient ratios? Where was the forgiveness or support then? Units have been reprimanded for a coffee cup at the nurses' station but are now expected to tolerate suggestions to throw on reused masks, or scarfs. Suddenly, chaos is an excuse, just not for us.

The expectations to which we've been held are not equivalent to the standards against which we've been judged. I feel extremely fortunate at my place of employment, where we are greatly supported within the limits of the current scenario. This isn't about my personal experience. These concerns go beyond nurse managers, committees, or even an individual hospital. What we tolerate is based on national expectation.

Hard worlds make tough people. That extends across borders.

Quite frankly, I've always been more afraid of what comes along with living than I've ever been of dying. ***

Months before the days of toilet paper shortages, bombarded emergency departments and intensive care units, and deflecting nonsense accusations against Asian Americans in the face of a world pandemic, I hovered anxiously over a hospital tray next to my Egyptian classmate. We had to check all the Algerian patient's food, since his Halal preference was either ignored or not understood by the facility's staff.

Whatever you eat, we all need food. Physically and mentally, emotionally and spiritually, everyone requires nourishment for complete wellness.

The more social distancing between us, the closer we grow as a world. It's not "their" problem now ... it's all of ours. 